\title{
Implications for winter grazing managements and dead material on the performance of young cattle in spring
}

D.R. STEVENS ${ }^{1}$, B.R. THOMPSON ${ }^{1}$ and G.R. WOOD ${ }^{2}$

${ }^{1}$ AgResearch, Invermay Research Centre, Private Bag 50034, Mosgiel, New Zealand ${ }^{2}$ University of Otago, Department of Mathematics and Statistics, P.O. Box 56, Dunedin 9054, New Zealand

david.stevens@agresearch.co.nz

\section{Abstract}

Data from an experiment investigating the impacts of winter dead material content and winter grazing intensity on spring pasture productivity and botanical composition, were used to estimate the impacts of agronomic outcomes on the potential production of young cattle during spring. The experiment was replicated at two sites (heavy and light soil types of moderate to high fertility in a cool temperate climate). Q-Graze software was used to determine liveweight gain (LWG) and grazing days of Angus steers (300 kg starting liveweight) grazing the pastures during spring at a stocking density of 20 steers/ha (an overall stocking rate of approximately 4 steers/ha). The reduction in dead material by intensive winter grazing strategies increased the estimated quality of pasture available by $0.5 \mathrm{MJ} \mathrm{ME} / \mathrm{kg} \mathrm{DM}(\mathrm{P}=0.002)$. Spring pasture production was higher when winter dead material content was low or medium compared with a high winter dead material content, leading to a reduction in LWG of $0.38 \mathrm{~kg} \mathrm{LW} /$ day $(\mathrm{P}<0.05)$. The imposition of intensive winter grazing on pastures with medium proportions of dead material increased steer LWG in spring from 0.39 to $0.64 \mathrm{~kg} / \mathrm{day}$, and from 0.22 to $0.33 \mathrm{~kg} /$ day when high dead material content was present in winter $(\mathrm{P}<0.05)$. Total LWG/ha for spring was increased by using intensive grazing management to remove winter dead material, and with medium or high dead material content compared with using a lax grazing approach $(\mathrm{P}<0.05)$ in winter.

Keywords: cattle, dead material, grazing intensity, liveweight gain, spring, winter

\section{Introduction}

The use of winter grazing management has been well defined in terms of the effect of grazing intensity on production of ryegrass-based pastures, with Harris \& Brown (1970) demonstrating that intense grazing in winter was detrimental to spring pasture production. Intense grazing during winter can also been demonstrated to have on-going effects by delaying the onset of spring growth by up to 6 weeks (Harris \& Brown 1970; Black 1975, 1978). More recent research demonstrated that maintaining higher pasture covers during winter resulted in increased pasture growth in late-winter and spring (Coutinho et al. 1998).

Winter has traditionally been seen as a time to clean up pastures, grazing out the dead material to promote new growth for spring. Farmers generally use a mobstocking grazing management to help reduce the amount of dead material in the pasture sward in the hope of increasing pasture production and hence stock performance. However, recent research has shown ity may not remove all (Stevens et al. 2015), and that the remaining dead material has a significant impact on spring pasture production (Thompson et al. 2017). So dead material often remains, lowering spring pasture production, and lowering potential feed quality. Spring is the time of greatest pasture surplus, and so is a time when young cattle are often fed to appetite to maximise production efficiency. What are the implications of the performance of young cattle?

Science often measures the results of applying agronomic management practices as changes in pasture production, botanical composition and feed quality. While this provides initial information abou the difference between new technologies and current practice, it often stops short of providing farmers with information about the performance of the animal or system.

There have been a wide range of approaches used to determine the impacts of agronomic research results. These range from simple conversion of dry materia increases into potential feed requirements for a stocking unit (Malcolm et al. 2014), through to whole farm modelling (Heard et al. 2013) or farmlet experimentation (Eerens et al. 1992). Intermediate approaches may include converting the feed quantity and quality into a poter ani peforme parter such as (Stevens \& Stevens et al. 2015), or milk production (Stevens \& Knowles 2011). Further expansion of the approach was to model standard farm systems and estimate the value of extra dry material production in different season when added as a marginal improvement (McEvoy et al. 2011; Chapman et al. 2012). Finally, an approach may be taken to investigate the optimal farm system that 
may use the new technology, potentially implementing new or different enterprises than are currently being employed (Rendel et al. 2015)

Each of these approaches has different outcomes and different levels of impact. A simple conversion of dry matter and quality data to animal performance provides a first step in understanding the potential of the technology. This paper examines the impacts of dead material and grazing strategies in winter on likely performance of young cattle in the following spring, using the Q-Graze software to convert pasture production and botanical composition data from an agronomic experiment into predicted LWG and stocking densities.

\section{Materials and methods}

Data from an experiment investigating the impacts of winter dead material content and winter grazing intensity on spring pasture productivity and botanical composition, replicated at two sites (heavy and light soil types of moderate to high fertility in a cool temperate climate) were used to estimate the impacts of agronomic outcomes on the potential production of young cattle during spring. A detailed description of the experiment on the two sites is documented (Thompson et al. 2017) and is briefly summarised here. The experiment was located at the AgResearch Invermay Research Centre (site 1), Mosgiel New Zealand (45085'S, $170^{\circ} 39^{\prime} \mathrm{E}$ ) and at AgResearch Winchure Resea Zealand $\left(45^{\circ} 79^{\prime} \mathrm{S}, 171^{\circ} 78^{\prime} \mathrm{E}\right)$ over the winter/spring of 2012. A factorial design compared three winte pasture dead material concentrations (high (50-70\% dead material), medium (30-50\%), low (10-30\%)) at either of two winter grazing intensities, leaving pasture residuals of $1200 \mathrm{~kg} \mathrm{DM} / \mathrm{ha}$ (lax) and $600 \mathrm{~kg} \mathrm{DM} / \mathrm{ha}$ (intense), replicated three times at each site. Pasture data were collected from five grazingevents at one site and six grazing events at the other between August and late November, after pastures of low, medium or high dead material content had been subject to intense or lax grazing.

This paper reports on translating those results into the potential of the pastures to provide weight gain of Angus steers (300 kg starting liveweight) grazing the pasture during spring at a stocking density of 20 steers/ha, with an overall stocking rate of approximately four to five steers/ha over the five grazing periods from August to late November. Q-Graze software (Woodward $e$ al. 2001) was used to determine LWG and grazing days. In brief, the Q-Graze software uses the botanical components of the pasture, along with ambient mean maximum temperature (Figure 1) to predict feed quality and intake. Animal parameters include gender, liveweight, and breed (as an indicator of final size). The amount of pasture on offer, the stocking rate and the area available are all input by the user.

The botanical composition data from the spring of 2012 was converted into units appropriate for the Q-Graze software. These included: dead material, as a percentage of total; clover as a percentage of green; and green grass leaf as a percentage of grass. The use of these botanical parameters provides three components that are independent of one another. Preand post-graing pasture masses (Table 1) were chosen to match those recorded during the physical experiment Thompson et al. 2017)

Results from the physical experiment and the modelling are presented as the actual pre- and postgrazing herbage mass, and calculated potential feed quality, animal LWG, feed intake, stocking rate and output/ha. Data were analysed using repeated measures REML analysis (Genstat v17).

\section{Results}

The major impact of winter pastures on spring LWG was due to the dead content of the pasture (Table 1). The reduction in dead material by intensive winter grazing strategies increased the estimated quality of pasture available by $0.5 \mathrm{MJ} \mathrm{ME} / \mathrm{kg} \mathrm{DM}(\mathrm{P}=0.002)$.

More pasture was available from pastures with low or medium contents of dead material in winter than pastures with a high dead material content (Table 1). The relative difference The relativ ( $\mathrm{P}=0.001)$, though total dead material did decline over the course of spring (Thompson et al. 2017). However, this dead material had a significant influence on the predicted pasture and diet energy concentration (Table 1) and subsequently on feed intake and daily LWG. A high concentration of dead material in winter led to lower pasture production in spring and, when combined with the poorer quality pasture, 2 inted in a redection $\mathrm{kg} \mathrm{LW} / \mathrm{day}(\mathrm{P}<0.05)$. The grazing days achieved on the swards with different winter dead material content was not significantly different (Table 1).

There was a significant interaction between grazing intensity and winter pasture dead material content (Table 2). Intense winter grazing was able to reduce the spring dead material content of pastures when they had been at medium or high dead material in winter. The impostion of intensive winter graing wher. The inposion of intive wister grazing LWG of rising 2 year old steers in sp ing fin 0.39 to $0.64 \mathrm{~kg} / \mathrm{day}$, and from 0.22 to $0.33 \mathrm{~kg} / \mathrm{day}$ when high dead material content was present in winter (Table 2, $\mathrm{P}<0.05$ ). When converted to total $\mathrm{LWG} / \mathrm{ha}$ for spring, the use of intensive grazing management to remove winter dead material provided increases of 62 and 58 $\mathrm{kg} / \mathrm{ha}$ (Table 2) from pastures with medium or high

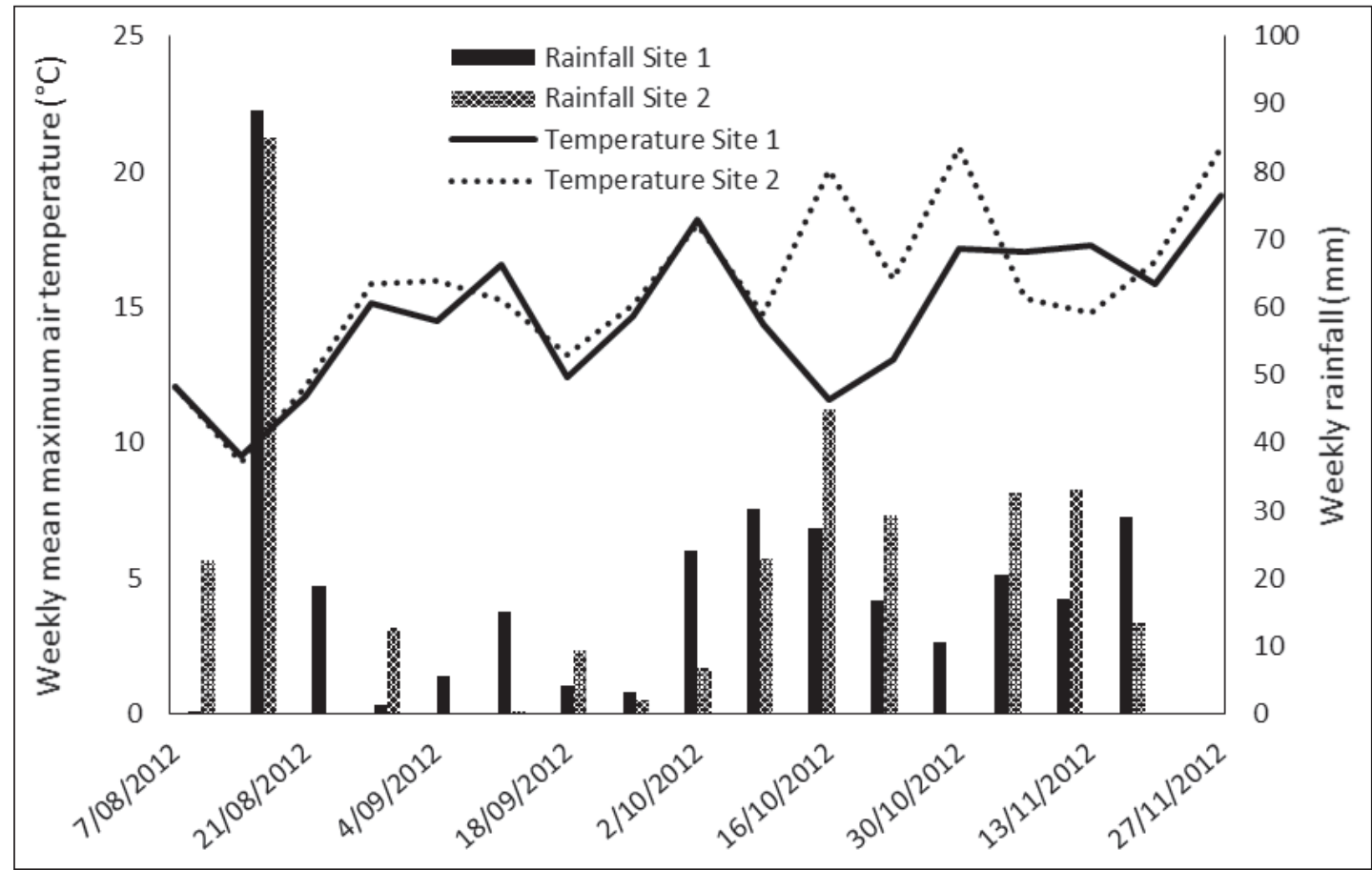

Figure 1 Weekly mean maximum air temperature and rainfall at two sites during a spring grazing experiment.

dead material content, compared with using a lax grazing approach $(\mathrm{P}<0.05)$ in winter.

Lax grazing in winter did not reduce dead material content in spring by as much and so resulted in lower animal productivity, both per head and per hectare. However, the variation in grazing days meant that an interaction between winter grazing intensity and dead material was not evident in total spring LWG/ha.

\section{Discussion}

Potential spring production of young cattle was 407 $\mathrm{kg} \mathrm{LW/ha}$ when pastures had low dead material in winter, but this was reduced to $126 \mathrm{~kg} \mathrm{LW} / \mathrm{ha}$ where pastures had high dead material, regardless of attempts to remove the dead material by targeting low residual pasture covers during winter grazing (intense grazing). The use of an intense winter grazing management

Table 1 Main effects of winter grazing and overwinter dead content of pastures on spring LWG of young beef cattle.

\begin{tabular}{|c|c|c|c|c|c|c|c|c|}
\hline & & \multicolumn{3}{|c|}{ Grazing } & \multicolumn{4}{|c|}{ Dead Content } \\
\hline & & Intense & Lax & $\mathrm{LSD}_{5 \%}$ & Low & Medium & High & $\mathrm{LSD}_{5 \%}$ \\
\hline \multirow[t]{6}{*}{ Pasture } & On offer (kg DM/ha) & $1930 \mathrm{~b}$ & $2060 \mathrm{a}$ & 86 & 2050a & $2060 \mathrm{a}$ & $1870 \mathrm{~b}$ & 105 \\
\hline & Residual (kg DM/ha) & 1330 & 1380 & 52 & 1340 & 1380 & 1350 & 63 \\
\hline & Dead material (\% of total) & $25.6 \mathrm{~b}$ & $35.0 \mathrm{a}$ & 4.1 & $22.1 \mathrm{c}$ & $28.6 \mathrm{~b}$ & $41.3 \mathrm{a}$ & 5.1 \\
\hline & Clover (\% of green) & 4.0 & 5.1 & 1.3 & $3.6 \mathrm{~b}$ & $4.7 \mathrm{ab}$ & $5.3 \mathrm{a}$ & 1.6 \\
\hline & Grass leaf (\% of grass) & 94.1 & 94.8 & 2.00 & 94.1 & 94.0 & 95.2 & 2.5 \\
\hline & Pasture energy content (MJ ME/kg DM) & $9.52 \mathrm{a}$ & $8.97 \mathrm{~b}$ & 0.23 & $9.79 \mathrm{a}$ & $9.34 \mathrm{~b}$ & $8.60 \mathrm{c}$ & 0.29 \\
\hline \multirow[t]{6}{*}{ Animal } & Diet energy content (MJ ME/kg DM) & $10.6 \mathrm{a}$ & $10.2 \mathrm{~b}$ & 0.16 & $10.7 \mathrm{a}$ & $10.5 \mathrm{~b}$ & $10.0 \mathrm{c}$ & 0.19 \\
\hline & Intake (kg DM/head/day) & $6.71 \mathrm{a}$ & $6.46 \mathrm{~b}$ & 0.22 & $6.98 \mathrm{a}$ & $6.69 \mathrm{~b}$ & $6.08 \mathrm{c}$ & 0.26 \\
\hline & Daily LWG (kg/head/day) & $0.54 \mathrm{a}$ & $0.42 \mathrm{~b}$ & 0.08 & $0.65 \mathrm{a}$ & $0.52 \mathrm{~b}$ & $0.27 \mathrm{c}$ & 0.10 \\
\hline & Grazing days (per grazing event) & $87 \mathrm{~b}$ & $105 \mathrm{a}$ & 15 & 102 & 100 & 88 & 19 \\
\hline & LWG (kg/ha/grazing) & 55 & 50 & 17 & $74 a$ & $60 \mathrm{a}$ & $23 \mathrm{~b}$ & 21 \\
\hline & Spring LWG (kg/ha) & 302 & 274 & 40 & $407 a$ & $330 \mathrm{~b}$ & $126 \mathrm{c}$ & 49 \\
\hline
\end{tabular}


approach on swards with a moderate concentration of dead material did improve steer LWG in spring.

While cleaning up dead material in winter provided some improvement in productivity when dead material was moderate, the impact of high levels of winter dead material on spring pasture and animal productivity is of critical interest to farmers, as it means that the long-held strategy of cleaning up pastures in winter and using a deferred grazing approach to manage surplus summer pasture growth, is only relevant in some circumstances. It also indicates that it is better to maintain pasture with low amounts of dead material, if the potential high productivity of spring pasture growth is to be harvested as animal LWG. This information provides evidence that the strategy of deferring grazing of surplus pasture production until mid-winter may reduce overall farm performance, or certainly the performance from parts of the farm. A greater alignment of animal demand with pasture supply during spring and summer does help reduce this build-up (Lambert \& Litherland 2000). climate and thus pasture production, means this strategy can be hard to implement on a regular basis. New grazing strategies need to be investigated to provide options for farmers to mitigate this effect.

The interaction between grazing intensity and pasture dead material c suggests that mode improved by gazing man spring production will not be compromised, and that even the performance of high dead material conten pastures can be improved. However, there are othe consequences of this strategy, as actual feed intake using these intensive grazing managements are usually low (Stevens et al. in prep.) and that most of the impact is coming from trampling of feed. This produces dilemma of balancing winter feed intake with future performance. While cattle are traditionally used in will depend on the extent of dead material build-up the previous growing season, the balance of ewes and cows available, and the potential environmental impacts of cattle treading in winter. Grazing strategies using single bearing ewes and specific grazing indices to predict pasture 'clean-up' power are being developed from further experimentation (Stevens et al. in prep.)

\section{Conclusions}

The efficient use of spring pasture is a key tenet for profitable beef production. This research demonstrates that pastures with significant dead material present in winter cannot be returned to a condition to achieve this aim, regardless of winter grazing intensity. Pastures must enter the winter with medium or low amounts of dead material present to enable high growth rates of young cattle in spring. Future research needs to examine the value of reducing or removing dead material before winter to avoid this situation altogether.

\section{ACKNOWLEDGEMENTS}

The authors would like to acknowledge the Ministry of Business, Innovation and Employment, DairyNZ, Fonterra, Beef + Lamb New Zealand and DCANZ for funding. The authors would also like to acknowledge the AgResearch Farm Systems and Farm field teams for technical support.

\section{REFERENCES}

Black, W.J.M 1975. Winter grazing of pasture by sheep. 1. Some effects of sheep stocking density on permanent pasture, including sward recovery, botanical composition and animal performance assessments. Irish Journal of Agricultural Research. 14: $275-284$.

Black, W.J.M. 1978. Winter grazing of pasture by sheep. Irish Journal of Agricultural Research. 17: 131-140. Chapman, D.F.; Bryant, J.R.; McMillan, W.H.; Khaembah, E.N. 2012. Economic values for evaluating pasture plant traits. Proceedings of the New Zealand Grassland Association 74: 209-216.
Coutinho, H.B.; Matthews, P.N.P.; Morris, S.T. 1998 The effect of grazing management on pasture and animal production in late autumn to early spring period in a one year bull beef grazing system. Proceedings of the New Zealand Society of Animal Production 58: 236-238.

Eerens, J.P.J.; Dylan, D.L.; Miller, K.B. 1992. The ryegrass endophyte in a cool moist environment. Proceedings of the New Zealand Grassland Association 54: 157-160.

Harris, AJ; Brown, K. R. 1970. Some effects of winter grazing management on winter and subsequent spring productivity of a ryegrass-white clover pasture. Proceedings of the New Zealand Grassland Association 32: 191-197.

Heard, J.; Malcolm, B.; Jackson, T.; Tocker, J.; Graham, P.; White, A. 2013. Whole farm analysis versus activity gross margin analysis: a sheep farm example. AFBM Journal 10: 16-29.

Malcolm, B.; Smith, K.F.; Jacobs, J.L. 2014. Perennial pasture persistence: the economic perspective. Crop and Pasture Science 65: 713-720.

McEvoy, M.; O'Donovan, M.; Shalloo, L. 201 Development and application of an economic ranking index for perennial ryegrass cultivars. Journal of Dairy Science 94: 1627-1639.

Rendel, J.M.; Mackay, A.D.; Smale, P. 2015. Valuing on-farm investments. Journal of New Zealand Grasslands 77: 83-88.

Stevens, D.R.; Knowles, I. 2011. Identifying the need for pasture renewal and valuing the contribution of renewal on a dairy farm - Telford Dairy, a case study. Grassland Research and Practice Series 15: $211-$ 216.

Stevens, D.R. Wall, AJ : Thompson, B.R. 2015. Potential impacts of different spring grazing strategies on lamb finishing in hill country. Journal of New Zealand Grasslands 77: 131-140.

Thompson, B.R.; Stevens, D.R.; Wall, A.J.; Moss, R.A.; O'Neill, K.T.; Cox, N.R. 2017. Winter grazing and dead material effects on early spring pasture production. New Zealand Journal of Agricultural Research DOI: 10.1080/00288233.2017.1283633

Woodward, S.J.R.; Lambert, M.G.; Litherland, A.J.; Boom, C.J. 2001. Can a mathematical model accurately predict intake of grazing animals? Testing the Q-Graze model. Proceedings of the New Zealand Society of Animal Production 61: 4-7.

Table 2 Interaction between grazing intensity and winter pasture dead material content on pasture and animal performance.

\begin{tabular}{lcccccccc}
\hline & \multicolumn{7}{c}{ Intense } & Lax \\
\cline { 2 - 9 } & Low & Medium & High & Low & Medium & High & $\begin{array}{c}\text { LSD }_{5 \%} \\
\text { Interaction P } \\
\text { value }\end{array}$ \\
\hline Daily LWG (kg/head/day) & $0.65 \mathrm{a}$ & $0.64 \mathrm{a}$ & $0.33 \mathrm{bc}$ & $0.65 \mathrm{a}$ & $0.39 \mathrm{~b}$ & $0.22 \mathrm{c}$ & 0.14 & 0.001 \\
Dead material (\%) & $20.7 \mathrm{a}$ & $20.1 \mathrm{a}$ & $36.0 \mathrm{~b}$ & $21.3 \mathrm{a}$ & $37.1 \mathrm{~b}$ & $46.6 \mathrm{c}$ & 7.2 & 0.007 \\
Pasture energy content (MJ ME/kg DM) & $9.80 \mathrm{a}$ & $9.87 \mathrm{a}$ & $8.88 \mathrm{~b}$ & $9.80 \mathrm{a}$ & $8.81 \mathrm{~b}$ & $8.32 \mathrm{c}$ & 0.41 & 0.002 \\
Diet energy content (MJ ME/kg DM) & $10.75 \mathrm{a}$ & $10.76 \mathrm{a}$ & $10.23 \mathrm{~b}$ & $10.73 \mathrm{a}$ & $10.18 \mathrm{~b}$ & $9.82 \mathrm{c}$ & 0.27 & 0.016 \\
Intake (kg DM/head/day) & 6.98 & 6.93 & 6.21 & 6.98 & 6.45 & 5.94 & 0.37 & 0.189 \\
Grazing days (per grazing event) & 99.6 & 90.5 & 73.4 & 103.8 & 110.4 & 101.7 & 26.3 & 0.071 \\
Spring LWG(kg/ha) & 390 & 361 & 155 & 424 & 299 & 97 & 29 & 0.562 \\
\hline
\end{tabular}

